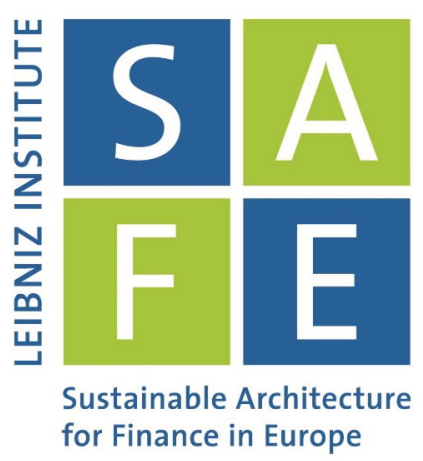

Monica Billio | Andrew W. Lo | Loriana Pelizzon | Mila Getmansky Sherman | Abalfazl Zareei

\title{
Global Realignment in Financial Market Dynamics: Evidence from ETF Networks
}

SAFE Working Paper No. 304

\section{Leibniz Institute for Financial Research SAFE}

Sustainable Architecture for Finance in Europe 


\title{
Global Realignment in Financial Market Dynamics:
}

\section{Evidence from ETF Networks}

\author{
Monica Billio, Andrew W. Lo, Loriana Pelizzon, \\ Mila Getmansky Sherman, Abalfazl Zareei
}

January 30, 2021

\begin{abstract}
The centrality of the United States in the global financial system is taken for granted, but its response to recent political and epidemiological events has suggested that China now holds a comparable position. Using minute-by-minute data from 2012 to 2020 on the financial performance of twelve country-specific exchange-traded funds, we construct daily snapshots of the global financial network and analyze them for the centrality and connectedness of each country in our sample. We find evidence that the U.S. was central to the global financial system into 2018, but that the U.S.-China trade war of 2018-2019 diminished its centrality, and the Covid-19 outbreak of 2019-2020 increased the centrality of China. These indicators may be the first signals that the global financial system is moving from a unipolar to a bipolar world.
\end{abstract}

Keywords: Network theory; Centrality; High Frequency Data; ETFs; Financial Crises; Covid-19; International Finance;

* Monica Billio: Ca' Foscari University of Venice, Department of Economics. Andrew W. Lo: MIT Sloan School of Management, Laboratory for Financial Engineering, MIT Computer Science and Artificial Intelligence Laboratory, MIT Department of Electrical Engineering and Computer Science. Loriana Pelizzon: Leibniz Institute for Financial Research SAFE, Goethe University, Ca' Foscari University of Venice, CEPR. Mila Getmansky Sherman: Isenberg School of Management, UMASS Amherst, Department of Finance. Abalfazl Zareei: Stockholm Business School, Stockholm University.

Corresponding Author: Mila Getmansky Sherman, msherman@isenberg.umass.edu (Email) 


\section{Introduction}

The United States is usually considered the center of the world's financial system. This was made dramatically clear during the financial crisis of 2008-2009, which originated in the U.S., transmitting itself to other countries from there. Yet the centrality of the U.S. in the global financial system is not limited to disruptive financial contagion. Returns to U.S. stocks have led those of other advanced economies for the last forty years, with shocks to returns in the U.S. predicting lagged returns in other countries, but not vice versa (Rapach, Strauss, and Zhou, 2013; Cieslak, Morse, and Vissing-Jorgensen, 2019).

Very recent financial data, however, indicates that the world has started to move from a unipolar to a bipolar system. Specific political and epidemiological forces, namely, the U.S.-China trade wars and the outbreak of Covid-19, have coupled China and the U.S. together in the global financial system (Acharya, Jiang, Richmond, and von Thadden, 2020; Antràs, Redding, and Rossi-Hansberg, 2020; Ossa, 2014; McKibbin and Fernando, 2020). These forces have made the international market system measurably less centered on the U.S.

High-frequency data is able to capture previously unrecognized patterns in the realtime dynamics of the market. It also makes it possible to calculate the origin and spread of informational and financial contagion from an individual financial market or specific financial instruments to the financial system as a whole (Gao, Han, Li, and Zhou, 2018; Hasbrouck, 1995). Using high-frequency intraday data, we can thus determine the network structure of the global financial system at any given moment, including the relative centrality of countries within it, and visualize the system's response to "innovations" such as trade wars and Covid-19. This network approach has been applied to economic and sociological analysis (Battiston, Farmer, Flache, Garlaschelli, Haldane, Heesterbeek, Hommes, Jaeger, May, and Scheffer, 2016; Diebold and Y1lmaz, 2014; Jackson, 2014; LeBaron and Tesfatsion, 2008; Mantegna and Stanley, 1995).

We focus our analysis on twelve country-specific exchange-traded funds (ETFs) for 
Australia, Canada, France, Germany, Italy, Japan, the Netherlands, Sweden, Switzerland, the United Kingdom, China, and the U.S. Our minute-by-minute high-frequency data comes from the New York Stock Exchange's Trade and Quote dataset from January 3, 2012 to May 29, 2020. Ernst (2020) concludes that ETFs can provide single-stock price discovery. Moreover, since all ETFs used in the analysis are traded on US exchanges, there is no need for timing synchronization which is imperative when comparing individual country stocks or indices.

The first attempt to estimate financial interconnectedness by examining the lead-lag relationship (Granger causality) between stock returns was proposed by (Billio, Getmansky, Lo, and Pelizzon, 2012); however, the authors used only lower frequency (i.e., monthly) returns in their analysis. Other proposed methods include using a multiplex financial network (Battiston et al., 2016), an agent-based network (LeBaron and Tesfatsion, 2008), production-based network (Gofman, Segal, and Wu, Forthcoming), an approach combining variance-decomposition and network topology theories (Diebold and Yilmaz, 2014), and a network based on intersectoral input-output linkages (Acemoglu, Carvalho, Ozdaglar, and Tahbaz-Salehi, 2012).

We use three methods to quantify the contagion between international markets: (i) vector autoregression (VAR) estimation; (ii) the machine-learning technique of least absolute shrinkage and selection operator (LASSO) estimation (Gu, Kelly, and Xiu, 2020); and (iii) variance decomposition (Diebold and Yilmaz (2014)). Each method allows us to construct a mathematical snapshot of the connections between the country-specific ETFs for each day in our dataset. From these snapshots, we are able to compute three network measures over time. Specifically we compute degree centrality from VAR estimation, Katz centrality from LASSO estimation, and net total directional connectedness from variance decomposition estimation.

All three methods depict a pattern of declining centrality for the U.S. and an increase in the centrality of China at the start of the trade war between the two countries, begin- 
ning with the U.S. implementation of global safeguard tariffs on February 7, 2018, and a memorandum to impose tariffs on Chinese products on March 22, 2018 (the initial U.S. imposition of Chinese-specific tariffs took place on July 6, 2018). We also capture a similar pattern leading up to the World Health Organization's announcement of the global Covid-19 pandemic on March 11, 2020. Our high-frequency financial data shows that China became central well before the announcement of tariffs or the pandemic.

The timing of the rise of the centrality of China and the outbreak of Covid-19 leads to the natural question of the relationship between network measures and the spread of the virus. We analyze the relationship between network measures (centrality and net total directional connectedness) to the daily increase in the number of Covid-19 cases in each individual country as reported by the World Health Organization (WHO-Report, 2020) by using a pooled regression approach. We find that there is a significant relationship between the number of new Covid-19 cases and our measures of centrality and net total directional connectedness. We therefore conclude that financial markets incorporate information from the epidemiological data.

When instead of using high-frequency ETF returns, we use daily returns data for stock indices and ETFs, no clear patterns emerge among country indexes even after accounting for timing synchronization. High-frequency data is forward-looking in capturing the rise of centrality of China. We show that since 2018, China has held a comparable position to the U.S. suggesting that the world has started to move from a unipolar to bipolar system.

The paper is organized as follows. Section 2 describes data and summary statistics. Section 3 describes methodology for contagion models and network measures. Section 4 provides results for these network measures. Section 5 provides results for Covid-19 analysis. Section 6 provides additional analysis and robustness results and we conclude in Section 7. 


\section{Data and Summary statistics}

\subsection{Exchange Traded Funds (ETF) List}

We focus on 12 country ETFs listed in Table 1. These countries encompass the 11 industrial countries examined in Rapach et al. (2013) and iShares MSCI China ETF. The iShares country ETFs, managed by BlackRock, have exposure to large and mid-sized companies in each country available to international investors, and thus are representative of each country's economy. ${ }^{1}$ These companies should be available to international investors and are included in corresponding country ETFs. We choose SPDR S\&P 500 ETF Trust as the US ETF. This ETF follows the S\&P 500 stock market index. Table 1 presents the ETF list.

Table 1: ETF List

The list of 12 country ETFs. This list comes from 11 industrial countries in Rapach et al. (2013) and iShares MSCI China ETF. The iShares MSCI ETF for each country exhibits exposure to large and mid-sized companies in their corresponding countries. These companies should be available to international investors for investment.

\begin{tabular}{clccl}
\hline \multicolumn{1}{c}{ Name } & Ticker & Country & Inception Date \\
\hline 1 & iShares MSCI Australia ETF & EWA & Australia & March 12, 1996 \\
2 & iShares MSCI Canada ETF & EWC & Canada & March 12, 1996 \\
3 & iShares MSCI France ETF & EWQ & France & March 12, 1996 \\
4 & iShares MSCI Germany ETF & EWG & Germany & March 12, 1996 \\
5 & iShares MSCI Italy ETF & EWI & Italy & March 12, 1996 \\
6 & iShares MSCI Japan ETF & EWJ & Japan & March 12, 1996 \\
7 & iShares MSCI Netherlands ETF & EWN & Netherlands & March 12, 1996 \\
8 & iShares MSCI Sweden ETF & EWD & Sweden & March 12, 1996 \\
9 & iShares MSCI Switzerland ETF & EWL & Switzerland & March 12, 1996 \\
10 & iShares MSCI United Kingdom ETF & EWU & United Kingdom & March 12, 1996 \\
11 & iShares MSCI China ETF & MCHI & China & March 29, 2011 \\
12 & SPDR S\&P 500 ETF Trust & SPDR & USA & January 22, 1993 \\
\hline
\end{tabular}

\subsection{Minute-by-minute returns}

Our high frequency data comes from the TAQ (Trade and Quote Database) dataset from January 3, 2012 to May 29, 2020. We choose January 2012 as the start date, since this is the earliest year for which data for all ETFs are available. The earliest date that all the ETF data is available is March 29, 2011, the inception date of the China ETF (MCHI).

\footnotetext{
${ }^{1}$ For example, the iShares MSCI China ETF on May 192020 has 17.73\% invested in Alibaba Group, $14.95 \%$ in Tencent Holdings, and 3.62\% in China Construction Bank Corp.
} 
The data is filtered following the steps in Holden and Jacobsen (2014). We remove quotes with abnormal quote conditions (mode value in TAQ equal to 4, 7, 9, 11, 13, 14, 15, $19,20,27,28)$, cross quotes on the same exchange (cross quotes are quotes from the same exchange that are both positive and the bid is higher than the ask), one-sided bid and ask quotes (for one-sided bid quotes, where the bid is positive and the ask is zero, we set the ask to an extreme value so it does not enter the NBO; for one-sided ask quotes, where the ask is positive and the bid is zero, we do not apply any adjustment), quotes with abnormally large spreads (positive quotes with spreads higher than \$5) and withdrawn quotes (when price or depth fields are less than zero or equal to '. ', we set the quotes equal to extreme values, e.g. $\$ 1$ million).

We compute and assign the average best bid-ask quote midpoint in each minute as the quote price of each minute. To avoid distortions in prices, we drop the first and last minute of each trading day in our sample. As a result, every day our minute-by-minute prices are observed from 9:31 A.M. to 3:59 P.M. leading to 389 daily price observations per ETF. For missing observations, we replace the missing return for any ETF in each minute by the average return in the cross-section in that minute. Our ETFs are traded in the United States market and are traded in the same time zone. Therefore, no time adjustment is needed for our VAR and LASSO lead-lag estimations.

Descriptive statistics for minute-by-minute returns (in basis points) for all country ETFs are reported in Table 2. 
Table 2: Descriptive statistics of ETF minute-by-minute returns

Summary statistics for the minute-by-minute returns from mid-point prices for each country-specific ETF. The ETF list is reported in Table 1. The minute-by-minute returns are in basis points. The sample is from January 3, 2012 to May 29, 2020.

\begin{tabular}{cccccccc}
\hline Num. & Country & Mean & Std & Skewness & Kurtosis & Min & Max \\
\hline 1 & Australia & 0.014 & 3.236 & 0.221 & 24.932 & -71.497 & 87.575 \\
2 & Canada & 0.006 & 3.424 & 0.587 & 48.500 & -133.674 & 181.037 \\
3 & France & 0.014 & 3.352 & 0.100 & 20.578 & -82.465 & 80.865 \\
4 & Germany & 0.013 & 3.354 & 0.058 & 20.945 & -78.889 & 77.496 \\
5 & Italy & 0.007 & 3.943 & -0.012 & 19.636 & -98.427 & 107.738 \\
6 & Japan & 0.013 & 2.707 & -0.012 & 23.959 & -93.233 & 63.528 \\
7 & Netherlands & 0.011 & 3.129 & 0.213 & 40.005 & -128.144 & 119.807 \\
8 & Sweden & 0.014 & 3.302 & 0.200 & 25.764 & -90.871 & 92.334 \\
9 & Switzerland & 0.013 & 2.634 & 0.125 & 32.108 & -89.974 & 87.040 \\
10 & United Kingdom & 0.011 & 2.997 & 0.097 & 18.838 & -60.390 & 66.93 \\
11 & China & 0.008 & 3.366 & 0.227 & 17.926 & -64.297 & 90.382 \\
12 & USA & 0.010 & 3.320 & 0.878 & 74.060 & -81.782 & 226.983 \\
\hline
\end{tabular}




\section{Contagion models and network measures}

We use three methods to quantify the contagion between international markets: (i) vector autoregression (VAR) estimation; (ii) the machine-learning technique of least absolute shrinkage and selection operator (LASSO) estimation; and (iii) variance decomposition. Each method allows us to construct a mathematical snapshot of the connections between the country-specific ETFs for each day in our dataset. From these snapshots, we are able to compute three network measures over time. Specifically we compute degree centrality from VAR estimation, Katz centrality from LASSO estimation, and net total directional connectedness from variance decomposition estimation. This section describes in detail all three methods and construction of three network measures.

\subsection{Vector Autoregression (VAR) Estimation}

Using the standard VAR method, we consider the following basic linear data-generating process for the market returns for each country ETF:

$$
r_{i, t}=a_{i}+\sum_{j=1}^{N} b_{i, j} r_{j, t-1}+\epsilon_{i, t}
$$

where $r_{i, t}$ is the return for country $i$ at time $t$, and $\epsilon_{i, t}$ is the noise term with $E\left[\epsilon_{i, t}\right]=0$ and $\operatorname{Var}\left[\epsilon_{i, t}\right]=\sigma_{\epsilon}^{2}$. We use the Akaike information criterion (AIC) with one-day minuteby-minute returns to check for the minimum number of lags in the VAR model, finding that one lag gives the lowest AIC value.

We estimate the above VAR(1) model for each country ETF in a rolling daily window to document any lead-lags in our data. This procedure generates a $12 \times 12$ set of coefficient estimates of $b_{i, j}$. Next, we build the adjacency matrix, $B$, using these estimated $b_{i, j}$ values. In this adjacency matrix, the element $B_{i, j}$ measures the impact of asset $j$ 's lagged return on asset $i^{\prime}$ s. 


$$
B=\left(\begin{array}{cccc}
b_{1,1} & b_{1,2} & \cdots & b_{1, N} \\
b_{2,1} & b_{2,2} & \cdots & b_{2, n} \\
\vdots & \vdots & \ddots & \vdots \\
b_{N, 1} & b_{N, 2} & \cdots & B_{N, N}
\end{array}\right)
$$

The matrix $B$ can be interpreted as a directed weighted network between countries, and the magnitude of each element as the strength of the connection. To measure the overall impact of lagged values of country $j$ on other countries, we define the degree centrality of country $i$ as:

$$
\text { Degree }- \text { centrality }_{j}=\sum_{i=1}^{N} b_{i, j}
$$

The higher the degree centrality of a country ETF, the greater its leading position. Although this definition of degree centrality may lead to negative values, our results are qualitatively the same when using squared coefficients.

We also estimate the Katz centrality:

$$
\text { Katz }- \text { centrality }_{j}=\left[\left(I-B^{\prime}\right)^{-1} . \mathbf{1}\right]_{j, 1}
$$

to capture higher-order relations between countries in the lead-lag network, similar to measures of the level of influence of a publication in a citation network.

\subsection{LASSO Estimation}

Motivated by the empirical fact that only a sparse set of predictors is important at any one time, we use the machine-learning technique of LASSO - a penalized regression algorithm — to estimate the lead-lag network (Chinco, Clark-Joseph, and Ye, 2019). For example, it is very rare that all twelve countries in our data set have commensurate effects on stock returns. Using the data-generating process in Equation (1) and a rolling daily 
window to document lead-lags among country ETFs, we apply LASSO to our dataset. LASSO works by formulating the regression as a convex optimization problem with a penalty parameter:

$$
\arg \min _{a_{i}, b_{i, j}}\left\{\frac{1}{T} \sum_{t=2}^{T}\left(r_{i, t}-a_{i}-\sum_{j=1}^{N} b_{i, j} r_{j, t-1}\right)^{2}+\lambda_{i}\left(\sum_{j=1}^{N}\left|b_{i, j}\right|\right)\right\}
$$

where $\lambda_{i}$ is the penalty parameter, setting all ordinary least squares coefficients smaller than itself to be zero. We estimate $\lambda_{i}$ using 10-fold cross-validation (Hastie, Tibshirani, and Friedman, 2001). Because LASSO is convexified and drops weak coefficients, we can estimate strong connections in a network using far fewer observations than the standard VAR method described earlier. We additionally no longer have the computational roadblock of applying an informational criterion to our data.

\subsection{Variance Decomposition Estimation}

We use variance decomposition approach to calculate the net total directional connectedness between country ETFs. In variance decomposition, rather than determining the pairwise strength of connection between the performances of country ETFs, the forecast error variance of a given country variable is decomposed into parts that are attributable to other variables (Diebold and Yilmaz (2014)). This approach measures the variation due to shocks from other parts of the overall system, and therefore is also useful in determining the directionality of a network.

Using Equation 1, we estimate $\mathbf{r}_{t}$ by reinterpreting the error term vector as a shock vector. In operator notation, this becomes:

$$
\mathbf{r}_{t}=\Omega(L) \epsilon_{t}
$$

where $\Omega(L)=(I-B L)^{-1}$, and $I$ is the identity matrix. We can then calculate the forecast error variance decomposition of an innovation shock of one standard deviation 
as follows:

$$
\gamma_{k j}^{H}=\frac{\sum_{t=0}^{H-1}\left(e_{k}^{\prime} C_{t} e_{j}\right)^{2}}{\sum_{t=0}^{H-1}\left(e_{k}^{\prime} \Omega_{t} \Sigma \Omega_{t}^{\prime} e_{k}\right)}
$$

where $\gamma_{k j}^{H}$ is the variance decomposition component of variable $\mathrm{k}$ due to shocks in variable $j$ forecast $H$ time steps ahead, and $e_{j}$ is a selection vector in which element $j$ is equal to unity and all other elements are zeros. When the shocks are orthogonal, $\Sigma$ is automatically equal to $\Omega_{t}$. However, this is typically not the case, and we will need to identify uncorrelated structural shocks. We approach this problem through the generalized variance decomposition (GVD) framework (Koop, Pesaran, and Potter, 1996; Pesaran and Shin, 1998), which is invariant to any ordering effects of the variables in the model. The GVD framework sets $C_{t}=\sigma_{j}^{-1} \Omega_{t} \Sigma$, where $\sigma_{j}$ is the standard deviation of innovation $j$.

After estimating $\gamma_{k j}^{H}$, we build the variance decomposition network for an H-step forecast as follows (Diebold and Yilmaz, 2014):

$$
D_{H}=\left(\begin{array}{cccc}
\gamma_{11}^{H} & \gamma_{12}^{H} & \cdots & \gamma_{1 N}^{H} \\
\gamma_{21}^{H} & \gamma_{22}^{H} & \cdots & \gamma_{2 N}^{H} \\
\vdots & \vdots & \ddots & \vdots \\
\gamma_{N 1}^{H} & \gamma_{N 2}^{H} & \cdots & \gamma_{N N}^{H}
\end{array}\right)
$$

We then can define a measure of total directional connectedness to others as the sum of row elements for each column in $D_{H}$, and the total directional connectedness from others as the sum of column elements for each row in $D_{H}$ (Diebold and Yilmaz, 2014). The net total directional connectedness is then the difference between the two values, formally defined as:

$$
\text { Net - Directional - Connectedness } s_{H}^{i}=\sum_{k=1, k \neg i}^{N} \gamma_{k i}^{H}-\sum_{j=1, i \neg j}^{N} \gamma_{i j}^{H}
$$




\section{Network results}

We compute three network measures: degree centrality from VAR estimation, Katz centrality from LASSO estimation, and net total directional connectedness from variance decomposition estimation. The lead-lag VAR and LASSO networks are estimated using minute-by-minute returns in each day. The time series of degree centrality for all 12 countries in our sample is depicted in Figure 1:A, while the time series of the Katz centrality is depicted in Figure 1:B, and the time series of the net total directional connectedness is shown in Figure 1:C. Centrality and net total connectedness values are averaged over 15-day rolling windows. Section 6.4 provides robustness checks using other windows for moving averages and our main results are consistent. ${ }^{2}$

All three methods depict a pattern of declining centrality for the U.S. and an increase in the centrality of China at the start of the trade war between the two countries, beginning with the U.S. implementation of global safeguard tariffs on February 7, 2018, and a memorandum to impose tariffs on Chinese products on March 22, 2018 (the initial U.S. imposition of Chinese-specific tariffs took place on July 6, 2018). We also capture a similar pattern leading up to the World Health Organization's announcement of the global Covid-19 pandemic was on March 11, 2020. Our high-frequency financial data shows that China became central well before the announcement of tariffs or the pandemic.

To emphasize this pattern, Figure 2 depicts the maximum values of our three network measures over time. When applied to our high-frequency data, all three methods again show the same pattern of Chinese centrality before major events. We observe that at the beginning of our sample, the U.S. was the center of the network in terms of information spillovers. Only in the last part of our sample did China become the central country (Figure 2:D). The three color-coded directed networks depict the one-day snapshot of the lead-lag network from the sparse LASSO estimation. The nodes in the networks represent

\footnotetext{
${ }^{2}$ In Appendix, we calculate degree centrality from LASSO estimation of the lead-lag relationships between country-specific ETFs and Katz centrality from VAR estimation of the lead-lag relationships between country-specific ETFs. The results are consistent with our main results.
} 
each country ETF and the edges depict the lead-lag relationship between the countries. The larger are the nodes, the higher is their degree centrality.

We then further zoom in on the time slightly before and after the WHO Announcement of the Covid-19 pandemic: October 2019 through the end of our sample, May 2020. We calculate and depict the performance of country index returns during this period for nonEuropean countries (Figure 3:A) and European countries (Figure 3:B). The markets have not reacted to initial lockdown in Hubei, China (January 23, 2020) or first Covid-19 cases in Europe (January 17, 2020), however, right after first lockdown measures in Italy (February 21,2020$)$ all international stock markets in our sample started to drop. The drop was especially pronounced around the first lockdown measures in the U.S (March 15, 2020) (Figure 3:A and 3:B). During this period we find that all international stock markets in our sample dropped at the same time with no identifiable leader or follower. Figure 3:C depicts Katz centrality measure from LASSO estimation procedure using minute-by-minute country ETF returns data from October 2019 to May 2020 for all countries in our sample. During this time period we observe an increase in centrality of China, peaking at the time of the WHO Announcement of Covid-19 pandemic (March 11, 2020). The network centrality highlights the relevance of China in providing information to the rest of the financial system (Figure 3:C). China is becoming the originating point for the spread of information to the rest of the world. It is important to emphasize that we show that return analysis is not adequate to capture this effect, and network analysis is essential. 

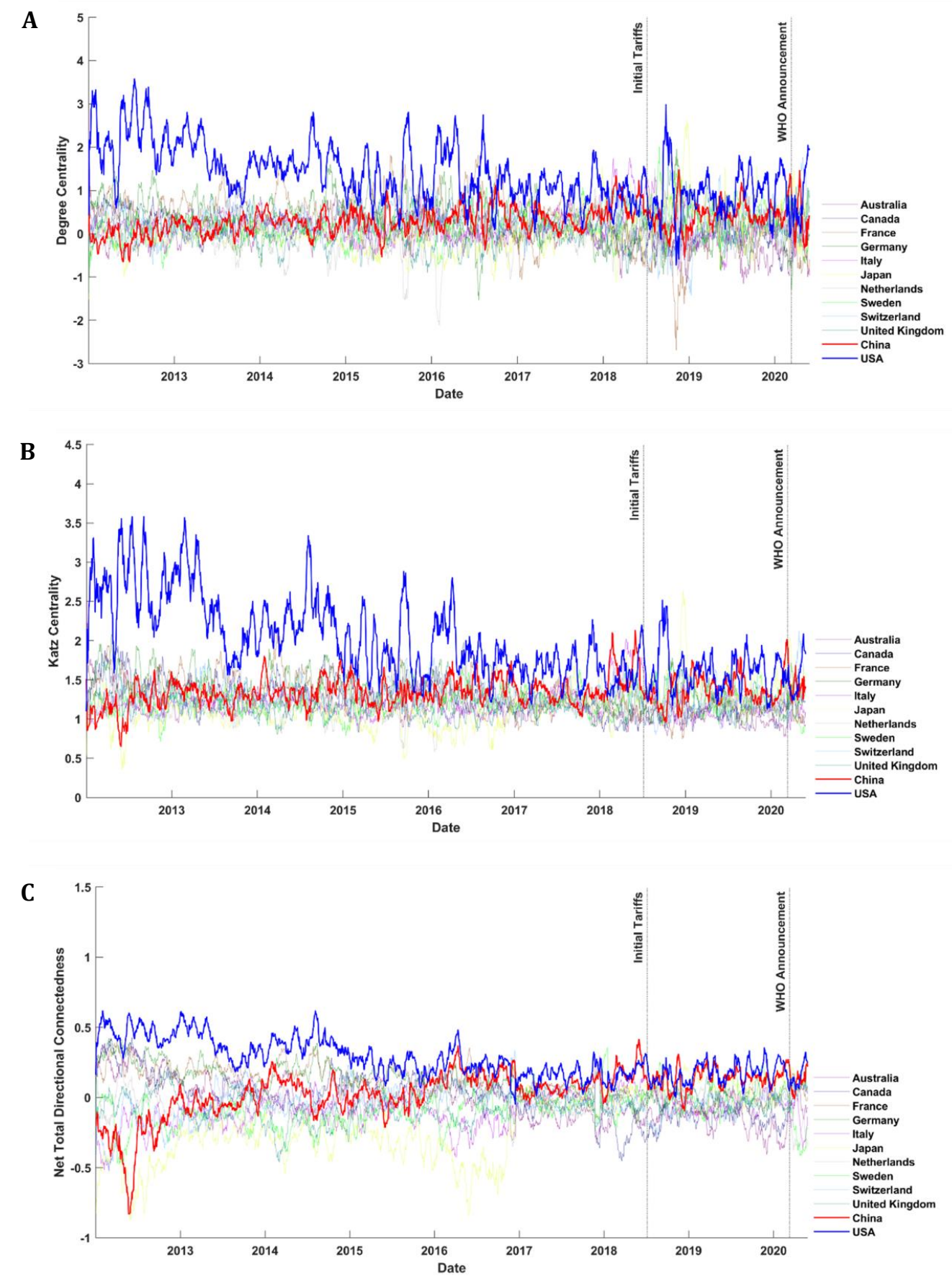

Figure. 1. Time series of network measures through time This figure presents the (A) degree centrality from VAR estimation; (B) Katz centrality from LASSO estimation; and (C) net total directional connectedness from variance decomposition estimation. The LASSO and VAR networks are estimated using minute-by-minute returns each day and the corresponding centrality and net directional connectedness values are averaged over 15-day intervals. The initial U.S. imposition of Chinese-specific tariffs took place on July 6, 2018 and the WHO's initial announcement of the Covid-19 pandemic occurred on March 11, 2020. 


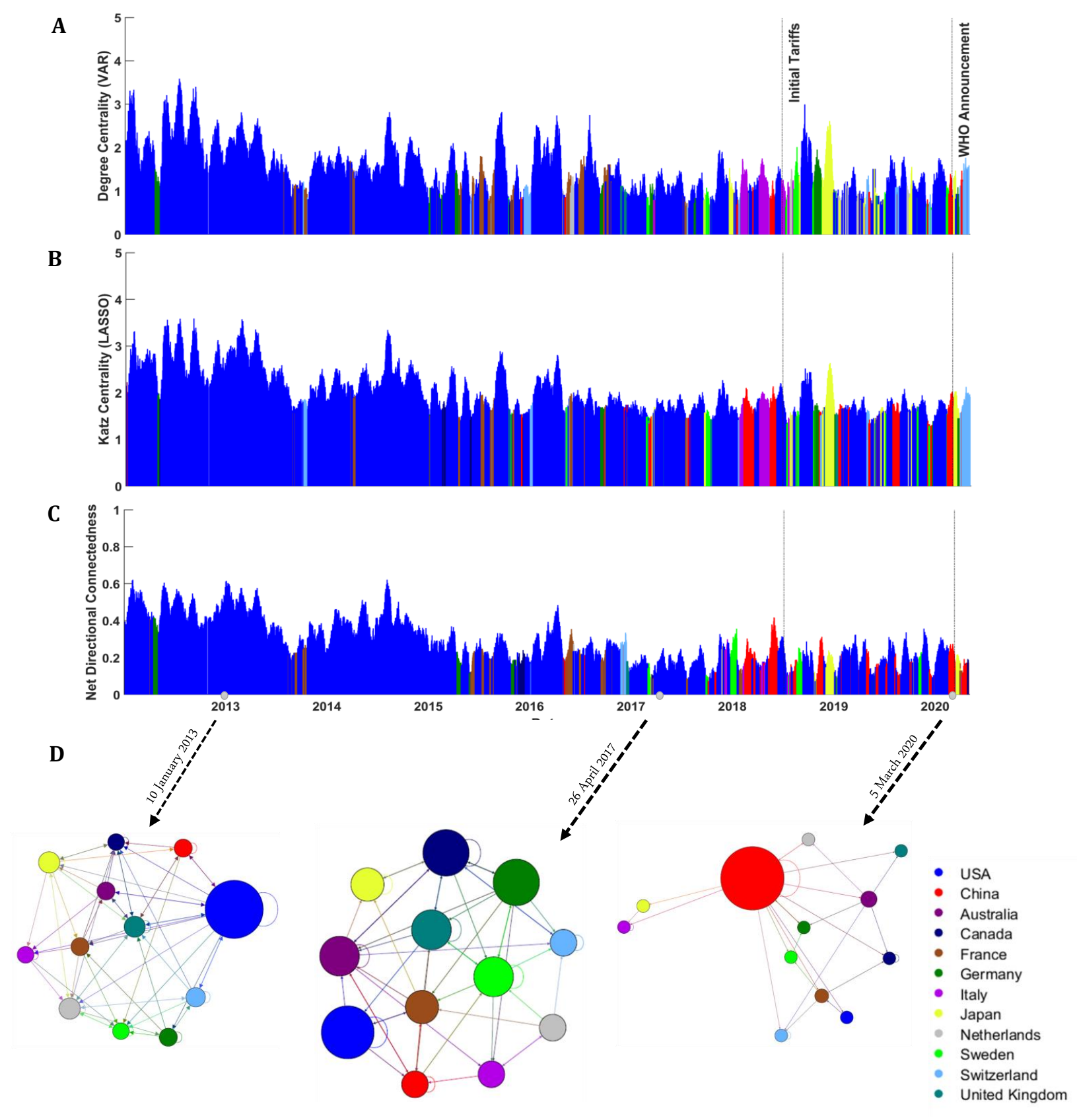

Figure. 2. Maximum country centralities and net total directional connectedness through time

Time series of maximum values of network measures through time: (A) Degree centrality using VAR estimation; (B) Katz centrality using LASSO estimation; and (C) Net total directional connectedness using variance decomposition. For each point in time, only the maximum value and corresponding country colour are depicted. The LASSO and VAR networks are estimated using minute-by-minute returns each day and the corresponding centrality and net directional connectedness values are averaged over 15-day intervals. The initial U.S. imposition of Chinese-specific tariffs took place on July 6, 2018 and the WHO's initial announcement of Covid-19 as a pandemic happened on March 11, 2020. (D) The three color-coded directed networks depict the one-day snapshot of the lead-lag network from the sparse LASSO estimation. The nodes in the networks represent each country ETF and the edges depict the lead-lag relationship between the countries. The larger are the nodes, the higher is their degree centrality. 

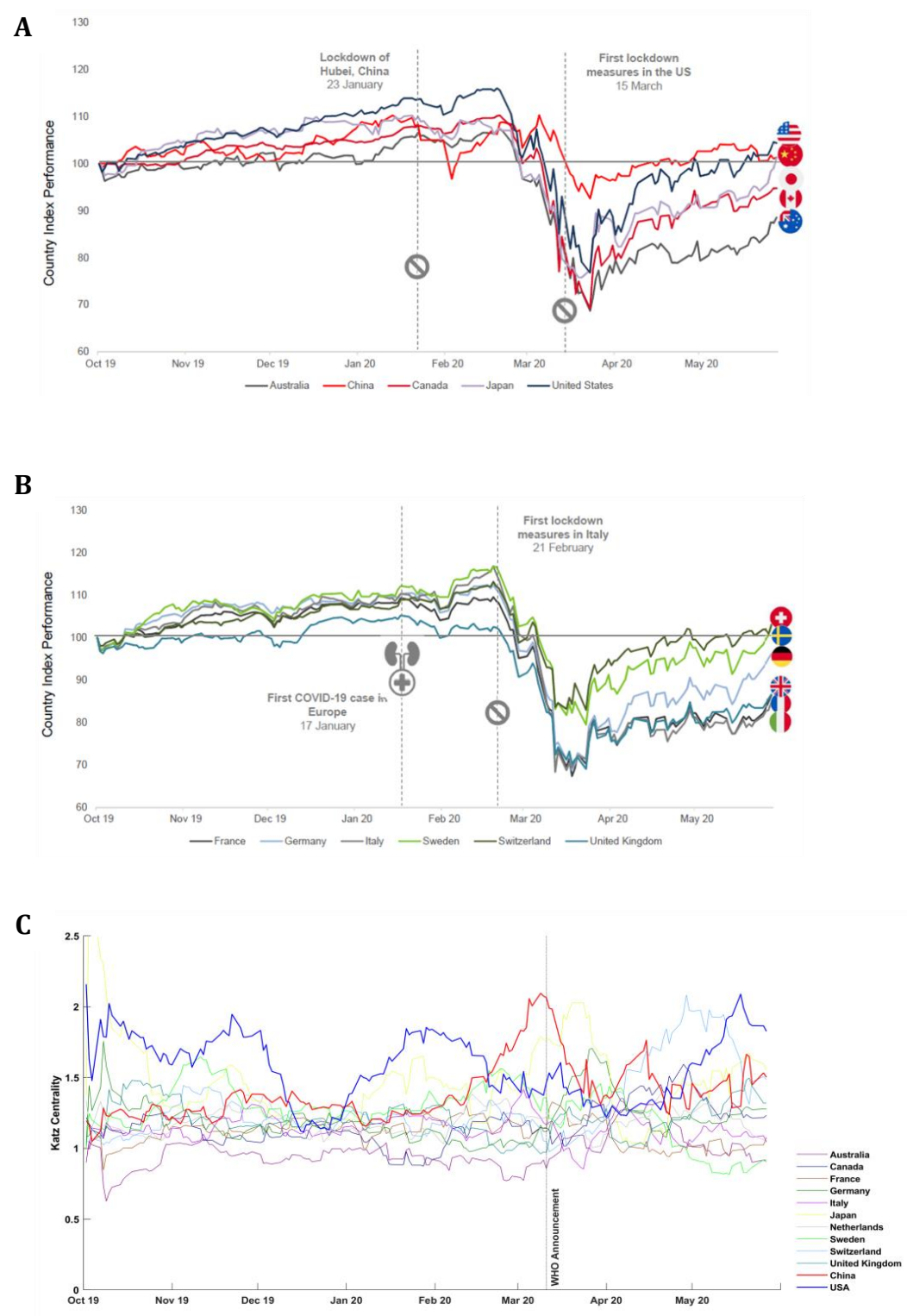

Figure. 3. Performance of country indexes and Katz centrality measure (A) Performance of non-European indexes from October 2019 to May 2020 using daily country index returns, (B) Performance of European indexes from October 2019 to May 2020 using daily country index returns, and (C) Katz centrality measure from LASSO estimation procedure using minute-by-minute country ETF data from October 2019 to May 2020. 


\section{Covid-19 Analysis}

The transmission dynamics of Covid-19 and their implications for hospital capacity, economic shutdowns, and global food security have been studied in several papers. This literature has grown impressively during the last six months (see Brodeur, Gray, Islam, and Bhuiyan (2020) for a broad overview). Here we posit a different question and ask whether the spread of Covid-19 is driving network measures. Specifically, we analyze whether there is any correlation between our calculated measures of centrality and connectedness and the past daily increase in the number of Covid-19 cases in each individual country. Each country enters the sample at the time of the first day of reported cases, e.g., for China, the data starts on January 13, and for Canada the data starts on January 27, 2020.

We run the following pooled regression to capture the predictive relationship between degree centrality; Katz centrality; and net total directional connectedness $\left(Y_{i, t+1}\right)$ to daily increase in Covid-19 cases (New_Cases $\left.{ }_{i, t}\right)$.

$$
Y_{i, t+1}=\beta_{0}+\beta_{\text {New_Cases }} N e w_{-} \text {Cases }_{i, t}+\beta_{Y} Y_{i, t}+\epsilon_{i, t}
$$

Table 3 provides summary statistics for variables used in the regression analysis, specifically different types of centrality and connectedness measures: degree_centrality, katz_centrality, degree_centrality lasso, katz_centrality lasso, and net total directional connectedness. Summary statistics for New_Cases, defined as daily change in Covid-19 cases are tabulated in Table 3. Covid-19 data comes from the World Health Organization. On average, there are 1,879 new cases each day with the maximum reaching 33,510 new daily cases.

Table 4 reports the results of the predictive relationship between degree centrality; Katz centrality; and net total directional connectedness $\left(Y_{i, t+1}\right)$ and daily increase in Covid19 cases $\left(\right.$ New_Cases $\left._{i, t}\right)$. Centrality measures are estimated using VAR, LASSO and variance decomposition estimation procedures. Table 4 shows that for all three network 
Table 3: Descriptive statistics

Summary statistics for variables used in the regression analysis Equation 10. The centrality values are computed using the VAR and LASSO estimation procedures. The net total directional connectedness is computed using variance decomposition method. The Covid-19 data comes from the World Health Organization. New_Cases is daily increase in Covid-19 cases.

\begin{tabular}{ccccccc}
\hline & Mean & Std & Skewness & Kurtosis & Min & Max \\
\hline New_Cases & 1,879 & 5,236 & 4 & 21 & -525 & 33,510 \\
Degree_Centrality & 0.248 & 1.825 & -0.039 & 4.840 & -7.627 & 7.915 \\
Katz_Centrality & 1.284 & 2.615 & -0.163 & 6.589 & -16.343 & 11.591 \\
Degree_Centrality_lasso & 0.218 & 0.625 & 0.683 & 11.609 & -3.531 & 4.156 \\
Katz_Centrality_lasso & 1.277 & 0.795 & 1.328 & 11.482 & -3.210 & 7.047 \\
Net Total Directional Connectedness & 0.003 & 0.269 & -0.237 & 4.320 & -0.972 & 1.032 \\
\hline
\end{tabular}

measures using three different estimation procedures, there is a significant relationship between increase in new Covid-19 cases and our measures of centrality and net total directional connectedness. We therefore conclude that financial markets incorporate information from the epidemiological data.

Table 4: Centrality, connectedness, and the spread of Covid-19: a pooled regression Results of the predictive relationship between centrality and connectedness and the increase in Covid-19 cases. The values for centrality and net total directional connectedness are computed using the VAR, LASSO and variance decomposition estimation procedures. Covid-19 data comes from the World Health Organization. New-Cases $i, t$ is the daily increase in Covid-19 cases reported for country $i$ on day $t$. Regression estimates are represented in basis points. The numbers in parentheses are $t$-statistics based on White (1980) standard errors. ${ }^{*}$ signifies $10 \%,{ }^{* *} 5 \%$ and ${ }^{* * *} 1 \%$.

\begin{tabular}{|c|c|c|c|c|c|}
\hline & \multicolumn{2}{|c|}{ VAR } & \multicolumn{2}{|c|}{ LASSO } & \multirow{2}{*}{$\begin{array}{l}\text { Variance Decomposition } \\
\text { Net_total_directional } \\
\text { connectedness }_{i, t+1}\end{array}$} \\
\hline & degree_centrality $_{i, t+1}$ & Katz_centrality $y_{i, t+1}$ & degree_centrality $_{i, t+1}$ & Katz_centrality $y_{i, t+1}$ & \\
\hline New_cases $_{i, t}$ & $\begin{array}{c}0.324^{* * *} \\
(2.98)\end{array}$ & $\begin{array}{c}0.535^{* * *} \\
(2.99)\end{array}$ & $\begin{array}{c}0.095^{* * *} \\
(2.82)\end{array}$ & $\begin{array}{c}0.129^{* * *} \\
(2.70)\end{array}$ & $\begin{array}{c}0.062^{* * *} \\
(4.52)\end{array}$ \\
\hline degree_centrality $_{i, t}$ & $\begin{array}{l}0.067^{*} \\
(1.85)\end{array}$ & & $\begin{array}{l}0.039 \\
(1.37)\end{array}$ & & \\
\hline Katz_centrality $y_{i, t}$ & & $\begin{array}{l}0.014 \\
(0.39)\end{array}$ & & $\begin{array}{l}0.037 \\
(1.20)\end{array}$ & \\
\hline $\begin{array}{l}\text { Net_total_directional } \\
\text { connectedness } s_{i, t}\end{array}$ & & & & & $\begin{array}{c}0.331^{* * *} \\
(10.78)\end{array}$ \\
\hline intercept & $\begin{array}{c}1778.933^{* * *} \\
(2.82)\end{array}$ & $\begin{array}{c}11739.567^{* * *} \\
(11.45)\end{array}$ & $\begin{array}{c}1949.215^{* * *} \\
(8.46)\end{array}$ & $\begin{array}{c}12071.128^{* * *} \\
(23.92)\end{array}$ & $\begin{array}{l}-96.84 \\
(-1.13)\end{array}$ \\
\hline$N$ & 953 & 953 & 953 & 953 & 953 \\
\hline$R^{2}$ & 0.014 & 0.012 & 0.008 & 0.009 & 0.135 \\
\hline
\end{tabular}




\section{Additional Results and Robustness Analysis}

In this section we conduct similar analysis as in the main text, but instead of using high-frequency ETF returns, we use daily returns data for stock indices and ETFs. We also conduct robustness analysis after accounting for timing synchronization and different lengths of moving averages.

\subsection{Daily Data Results - Indexes}

This section presents the results of our contagion analysis applied to daily index returns. Table 5 tabulates the names of the indexes and their corresponding tickers. Table 6 provides descriptive statistics for the indexes, and Figure 4 depicts the time series of the maximum value for country centralities and the net total directional connectedness using daily index data. As the figure shows, there is not a clear pattern in the network measures, and we cannot give a clear interpretation of the ranking of countries through time. One might argue that the pattern in lead-lags emerges because we do not consider the differences between opening and closing times of different countries' stock markets. In order to ensure this is not the case, and that it is the frequency of the data that influence our results, in the Section 6.3 we examine the open-close of daily ETFs and a modified version of the daily indexes using a lead-lag timing correction. 
Table 5: Index list

The list of 12 country indexes. This list comes from 11 industrial countries in Rapach et al. (2013) plus the Chinese market index (SSE).

\begin{tabular}{clcc}
\hline \multicolumn{1}{c}{ Name } & Ticker & Country \\
\hline 1 & S\&P/ASX 200 & AXJO & Australia \\
2 & S\&P/TSX Composite index & GSPTSE & Canada \\
3 & CAC 40 & FCHI & France \\
4 & DAX Index & GDAXI & Germany \\
5 & FTSE MIB Index & FTSEMIB.MI & Italy \\
6 & Nikkei 225 & N225 & Japan \\
7 & AEX-INDEX & AEX & Netherlands \\
8 & OMX Stockholm 30 Index & OMX & Sweden \\
9 & SMI PR & SSMI & Switzerland \\
10 & FTSE 100 & FTSE & United Kingdom \\
11 & Shanghai Stock Exchange & SSE & China \\
12 & S\&P 500 & GSPC & USA \\
\hline
\end{tabular}

Table 6: Descriptive statistics

Summary statistics for daily returns of the 12 country indexes in Table 5 . The returns are in percentages.

\begin{tabular}{cccccccc}
\hline Num. & Country & Mean & Std & Skewness & kurtosis & Min & Max \\
\hline 1 & Australia & 0.023 & 0.949 & -0.826 & 12.658 & -7.329 & 5.541 \\
2 & Canada & 0.018 & 0.888 & -2.268 & 30.234 & -9.886 & 5.063 \\
3 & France & 0.029 & 1.193 & -0.546 & 7.935 & -8.043 & 5.014 \\
4 & Germany & 0.045 & 1.180 & -0.37 & 6.481 & -6.823 & 5.676 \\
5 & Italy & 0.026 & 1.488 & -0.606 & 8.752 & -11.173 & 6.594 \\
6 & Japan & 0.049 & 1.274 & -0.118 & 7.392 & -6.351 & 7.156 \\
7 & Netherlands & 0.034 & 1.040 & -0.447 & 6.284 & -5.704 & 4.051 \\
8 & Sweden & 0.037 & 1.082 & -0.297 & 5.612 & -5.210 & 4.531 \\
9 & Switzerland & 0.028 & 0.928 & -0.725 & 7.783 & -5.964 & 3.423 \\
10 & United Kingdom & 0.012 & 0.946 & -0.429 & 6.715 & -5.251 & 4.29 \\
11 & China & 0.025 & 1.341 & -0.702 & 9.126 & -7.703 & 5.712 \\
12 & USA & 0.051 & 1.006 & -0.343 & 14.837 & -7.597 & 7.036 \\
\hline
\end{tabular}




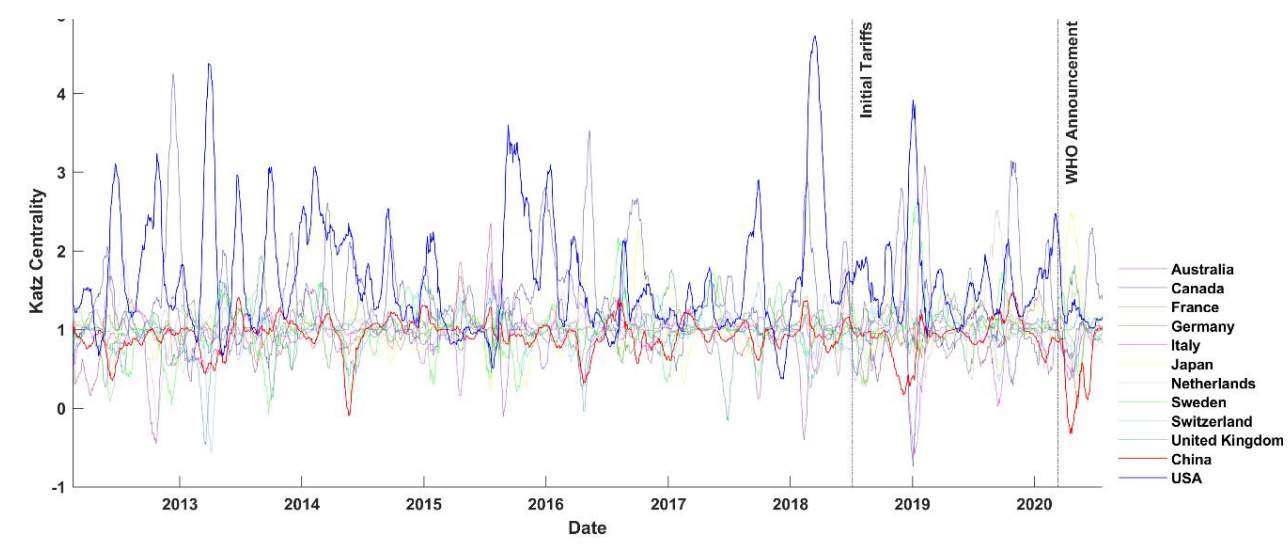

B

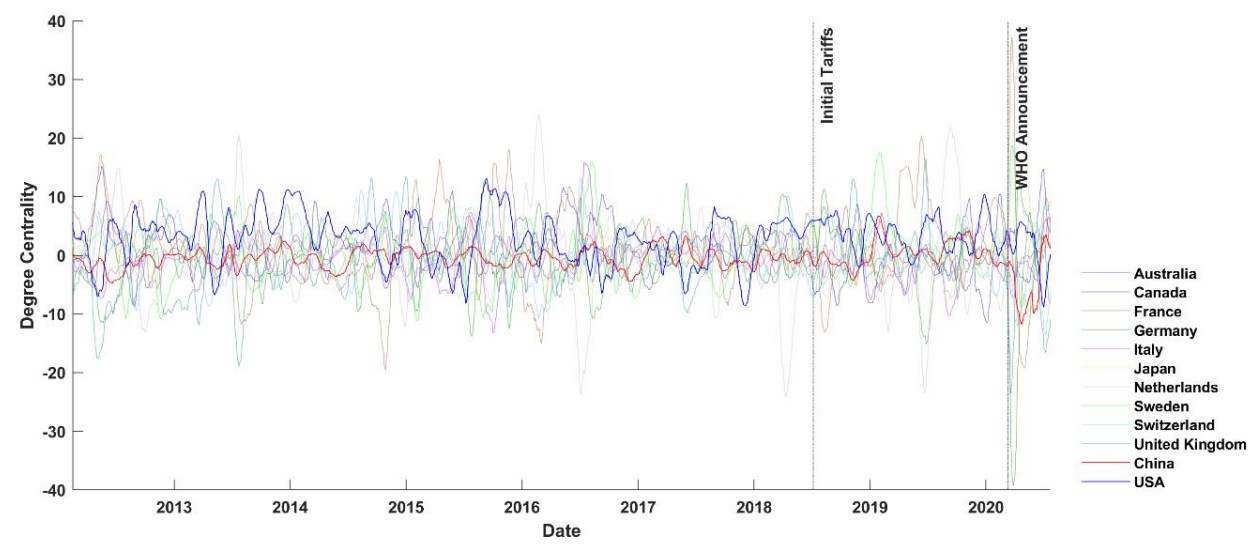

C

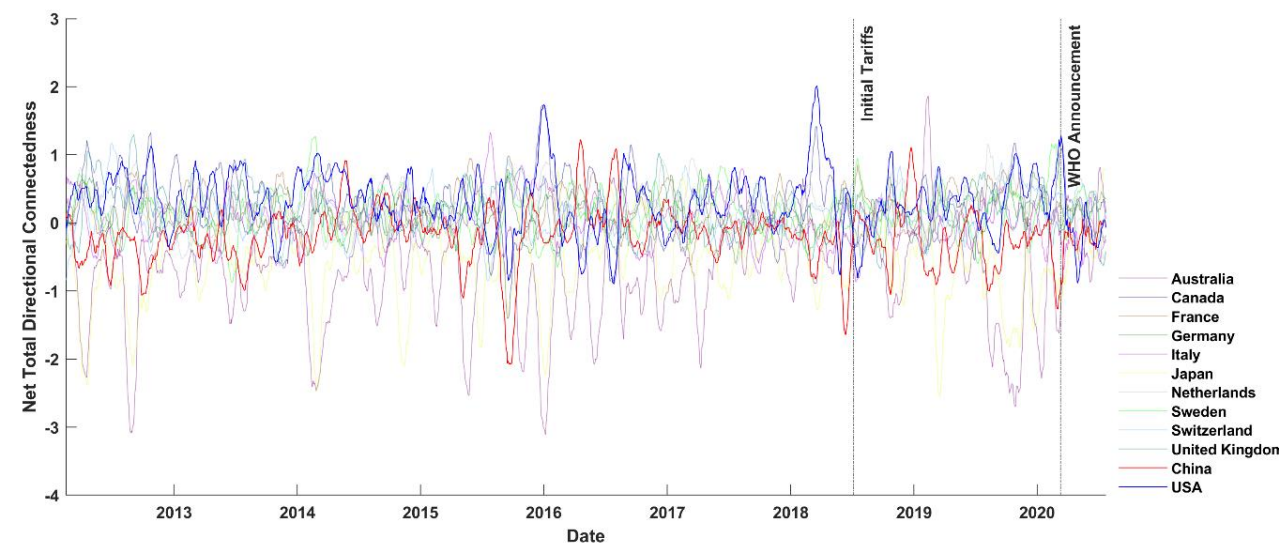

Figure. 4. Country centralities and net total directional connectedness through time (Daily Indexes)

Time series of network measures through time: (A) Katz Centrality from LASSO estimation; (B) Degree centrality from VAR estimation; and (C) Net total directional connectedness from variance decomposition estimation. The values are averaged over rolling 15-day intervals. The initial U.S. imposition of Chinesespecific tariffs took place on July 6, 2018 and the WHO's initial announcement of Covid-19 pandemic was on March 11, 2020. The VAR and LASSO networks are estimated in rolling 30-day intervals using daily index returns. 


\subsection{Daily Data Results - ETF}

We repeat the contagion analysis in the main text using the daily ETF returns. We compute the daily ETF returns using the mid-quote prices at the end of the day, at 15:59. Table 7 reports the summary statistics for daily ETF returns. Figure 5 depicts time series of maximum country centralities and net total directional connectedness through time using daily ETF returns.

Figure 5 depicts the leading country degree centrality, Katz centrality and net total directional connectedness from 2012 to the end of May 2020. Since all ETFs used in the analysis are traded inside the United States, there is no need for timing synchronization. There are no inherent patterns among countries using these network measures from the daily data. On the other hand, using ETF minute-by-minute returns, as described in the main results, the leading role of the United States is clear in the early years of our data.

Table 7: Descriptive statistics

Summary statistics for daily returns of the 12 country-specific ETFs. The returns are in percentages. The daily ETF returns are computed using the mid-quote prices at the end of the day.

\begin{tabular}{cccccccc}
\hline Num. & Country & Mean & Std & Skewness & kurtosis & Min & Max \\
\hline 1 & Australia & -0.001 & 1.412 & -0.891 & 17.081 & -11.927 & 8.564 \\
2 & Canada & 0.000 & 1.115 & -1.534 & 19.604 & -10.945 & 5.723 \\
3 & France & 0.020 & 1.296 & -1.044 & 14.864 & -11.339 & 6.32 \\
4 & Germany & 0.022 & 1.276 & -0.833 & 11.077 & -9.864 & 6.012 \\
5 & Italy & 0.013 & 1.628 & -0.862 & 12.514 & -13.366 & 8.263 \\
6 & Japan & 0.029 & 1.053 & -0.181 & 6.811 & -4.882 & 5.702 \\
7 & Netherlands & 0.034 & 1.164 & -1.051 & 12.539 & -9.560 & 5.196 \\
8 & Sweden & 0.016 & 1.370 & -1.040 & 11.648 & -11.143 & 6.013 \\
9 & Switzerland & 0.030 & 0.957 & -0.679 & 10.491 & -6.973 & 4.833 \\
10 & United Kingdom & 0.001 & 1.164 & -1.247 & 16.126 & -9.931 & 6.395 \\
11 & China & 0.036 & 1.431 & -0.177 & 4.954 & -6.636 & 5.956 \\
12 & USA & 0.044 & 0.978 & -0.337 & 14.64 & -7.467 & 6.969 \\
\hline
\end{tabular}




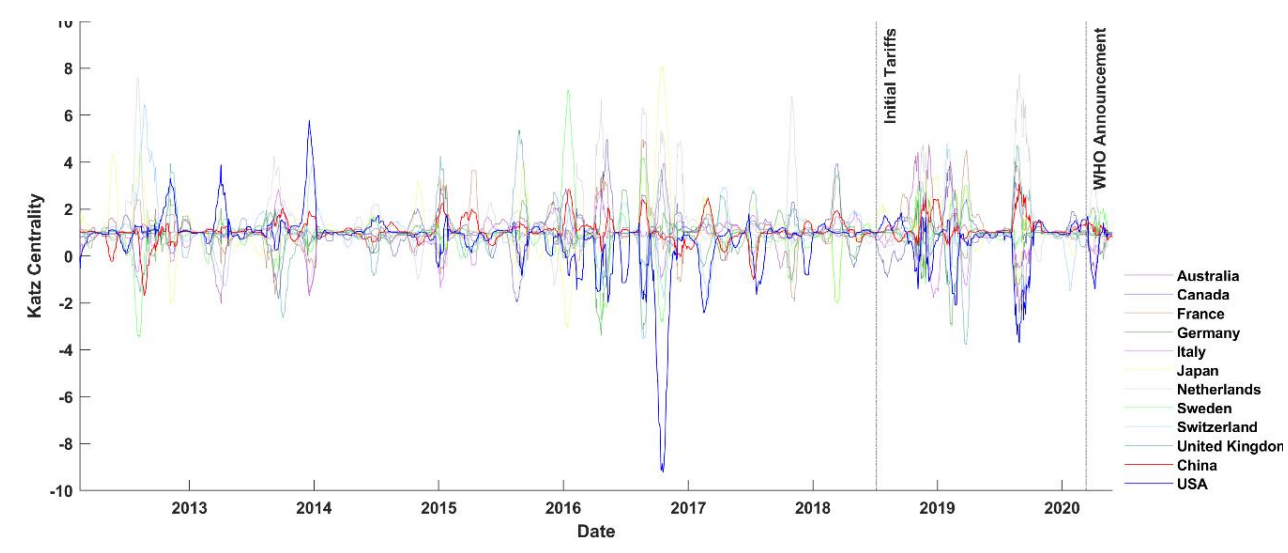

B

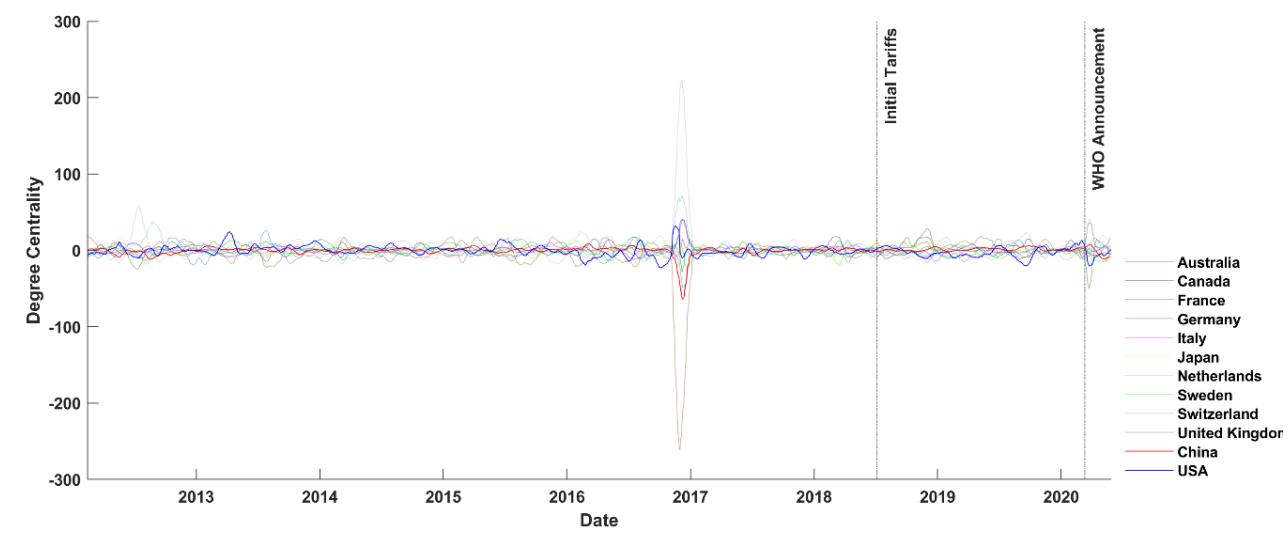

C

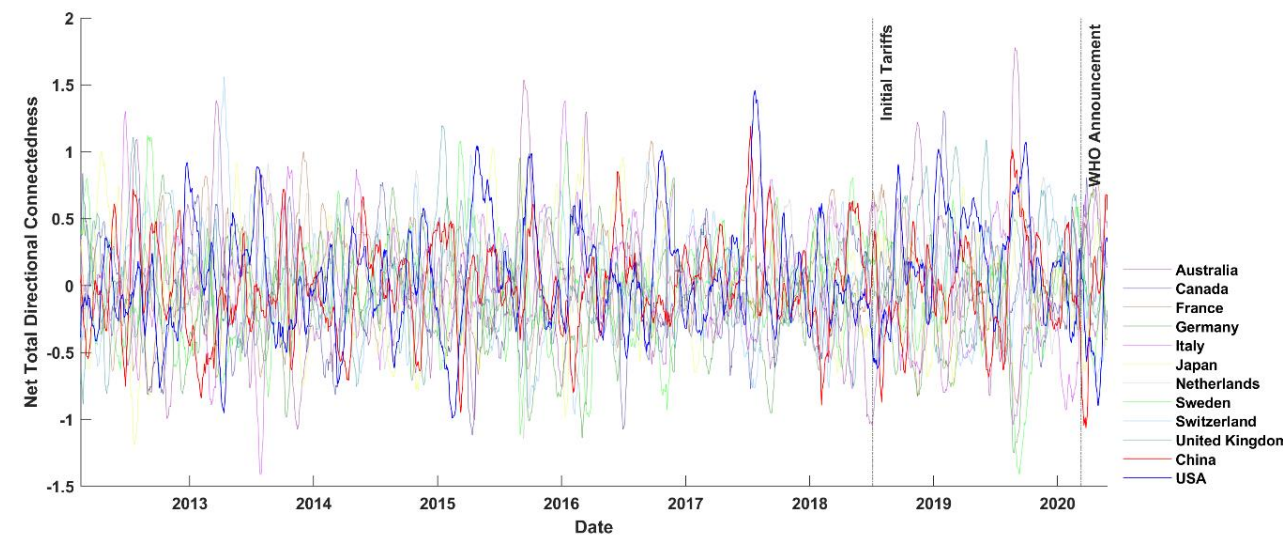

Figure. 5. Country centralities and net total directional connectedness through time (Daily ETF)

Time series of network measures through time: (A) Katz centrality from LASSO estimation; (B) Degree centrality from VAR estimation; and (C) Net total directional connectedness from variance decomposition estimation. The initial U.S. imposition of Chinese-specific tariffs took place on July 6, 2018 and the WHO's initial announcement of Covid-19 pandemic was on March 11, 2020. The VAR and LASSO networks are estimated using rolling 30-day intervals on daily ETF returns. 


\subsection{Daily Index Results with Timing Correction}

One could claim that the daily index results are not informative because the index returns are not synchronized correctly with respect to the opening of different international markets. Here, we propose a timing synchronization approach.

Table 8:A tabulates the opening and closing times of international stock exchanges. The stock markets open and close at different hours, and due to this timing disagreement, estimating a VAR model using daily returns to identify lead-lags between markets can be misleading. In Table 8:B, we propose a timing adjustment approach in the VAR estimation process. Depending on the country that is the dependent variable in the VAR estimation, we use a lagged or simultaneous form of the open-close returns of independent country indexes. For example, if the United States is the dependent variable, we use the sameday open-close returns of European and Asian countries and the lagged value of North American countries in the VAR estimation. This is because in one day (a day defined in the UTC system), the markets in Asia and Europe open before the market in the North America opens. We compute the daily open-close ETF returns using the mid-quote prices in the beginning of the day, at 9:31 and the mid-quote price at the end of the day, at 15:59. Table 9 reports the summary statistics of open-close index returns.

Figure 6 shows that no clear patterns emerge among country indexes using daily data even after accounting for timing synchronization. This confirms the advantage of highfrequency returns to extract lead-lags between countries' stock markets and to capture centrality in terms of information spillover. We note that another approach in dealing with timing synchronization is to use monthly returns and follow the procedure in (Rapach et al., 2013). However, in our setting, there are too few observations using monthly returns to compute a time-series picture of dynamic centralities. 
Table 8: Time Synchronization of Indexes

Panel A shows the UTC timing of market opening and closing in different countries. Europe* stands for Sweden, Italy, Germany, the Netherlands, and Switzerland. Panel B shows the lead-lag timing treatment of country indexes. Each day, $t$, is defined in UTC time format. We have three sets of countries: North America: US, Canada; Asia: Japan, China, Australia; Europe: France, United Kingdom, Sweden, Italy, Germany, the Netherlands, Switzerland.

\begin{tabular}{|c|c|c|c|c|c|c|c|}
\hline \multicolumn{8}{|c|}{ Panel A. Market open and close time } \\
\hline UTC TIME & USA & Canada & Europe* & UK & China & Japan & Australia \\
\hline 0 & & & & & & Tokyo & Australian \\
\hline 1 & & & & & Shanghai & Stock & Securities \\
\hline 2 & & & & & Stock & Exchange & Exchange \\
\hline 3 & & & & & Exchange & & \\
\hline 4 & & & & & $01: 30$ & & \\
\hline 5 & & & & & 07:00 & 00:00 & 00:00 \\
\hline 6 & & & & & & 08:00 & $06: 00$ \\
\hline \multicolumn{8}{|l|}{7} \\
\hline \multicolumn{8}{|l|}{8} \\
\hline 9 & & & Euronext & & & & \\
\hline 10 & & & Paris & London & & & \\
\hline 11 & & & & Stock & & & \\
\hline 12 & & & & Exchange & & & \\
\hline 13 & New York & Toronto & 08:00 & 08:00 & & & \\
\hline 14 & Stock & Stock & $16: 30$ & $16: 30$ & & & \\
\hline 15 & Exchange & Exchange & & & & & \\
\hline \multicolumn{8}{|c|}{ Excriange } \\
\hline 17 & $13: 30$ & $13: 30$ & & & & & \\
\hline 18 & $20: 00$ & $21: 00$ & & & & & \\
\hline \multicolumn{8}{|l|}{19} \\
\hline \multicolumn{8}{|l|}{20} \\
\hline \multicolumn{8}{|l|}{21} \\
\hline \multicolumn{8}{|l|}{22} \\
\hline 23 & & & & & & & \\
\hline
\end{tabular}

Panel B. Open to close return synchronization

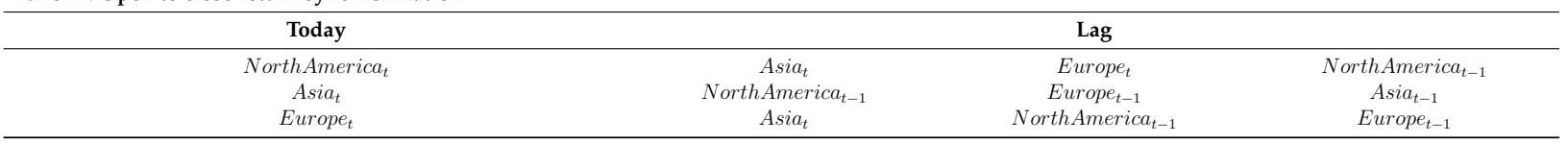

Table 9: Descriptive statistics (open-close index returns)

Summary statistics for daily open-close returns of the 12 country indexes described in Table 1 . The returns are in percentages.

\begin{tabular}{cccccccc}
\hline Num. & Country & Mean & Std & Skewness & kurtosis & Min & Max \\
\hline 1 & Australia & 0.022 & 0.935 & -0.799 & 12.825 & -7.329 & 5.541 \\
2 & Canada & -0.002 & 0.662 & -0.388 & 11.407 & -4.651 & 4.377 \\
3 & France & -0.005 & 0.911 & -0.189 & 4.956 & -3.687 & 3.994 \\
4 & Germany & -0.006 & 0.923 & -0.174 & 4.842 & -3.757 & 3.948 \\
5 & Italy & -0.041 & 1.294 & -0.891 & 11.346 & -11.092 & 5.57 \\
6 & Japan & 0 & 0.925 & -0.31 & 9.196 & -5.96 & 5.143 \\
7 & Netherlands & -0.002 & 0.812 & -0.143 & 5.842 & -3.66 & 4.308 \\
8 & Sweden & 0.005 & 0.915 & -0.384 & 5.194 & -4.737 & 3.354 \\
9 & Switzerland & 0.01 & 0.766 & -0.903 & 9.83 & -5.548 & 3.472 \\
10 & United Kingdom & 0.013 & 0.943 & -0.429 & 6.765 & -5.251 & 4.29 \\
11 & China & 0.123 & 1.179 & -0.306 & 7.857 & -6.523 & 5.147 \\
12 & USA & 0.028 & 0.815 & -0.426 & 8.63 & -4.883 & 4.389 \\
\hline
\end{tabular}




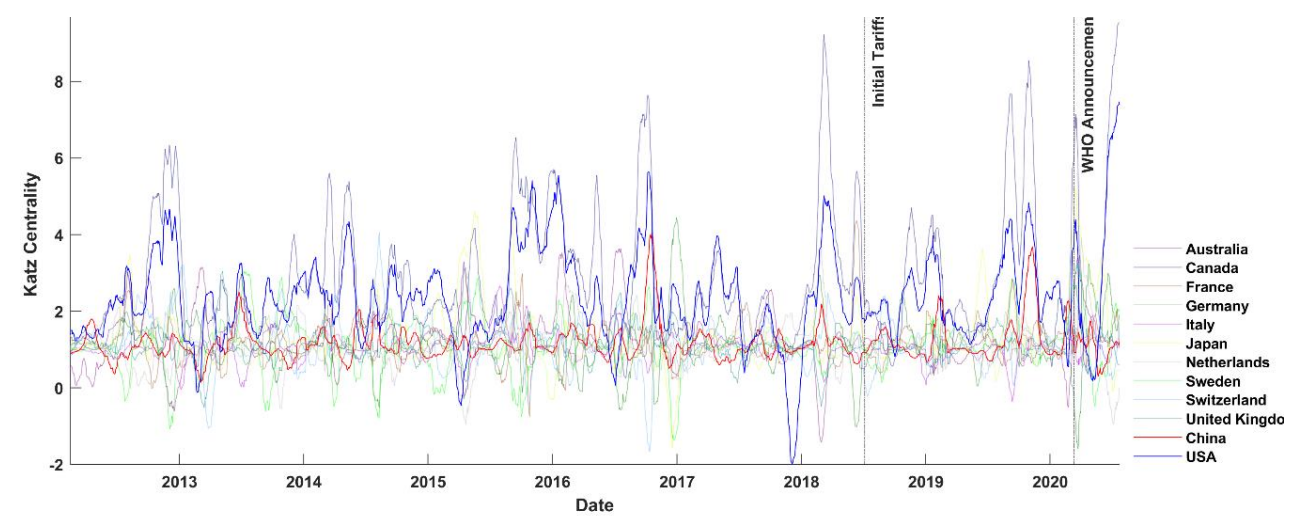

B

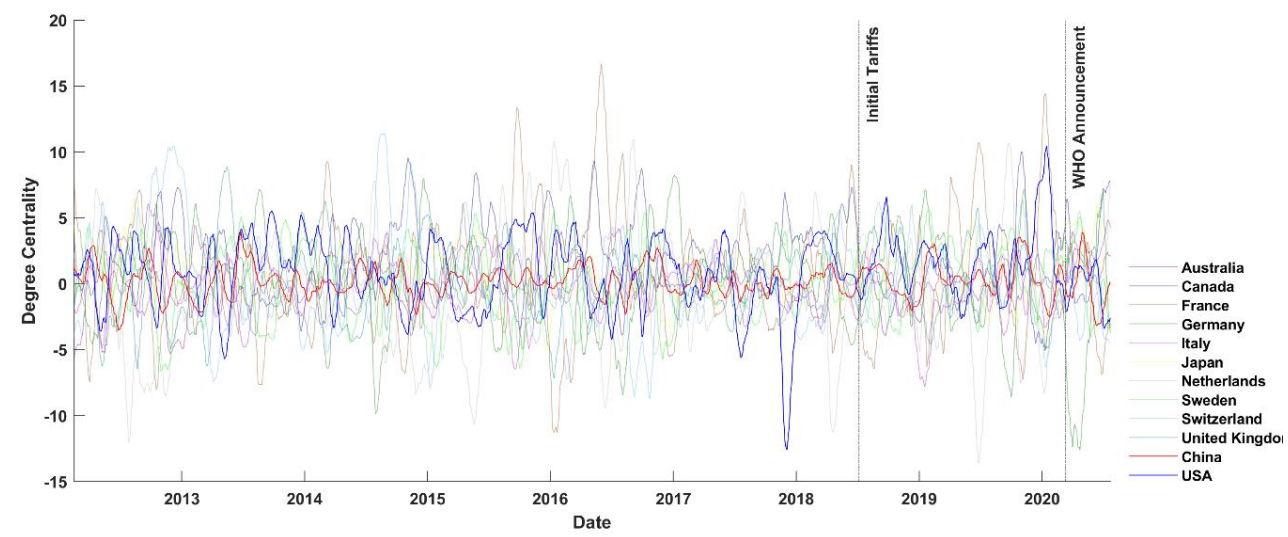

C

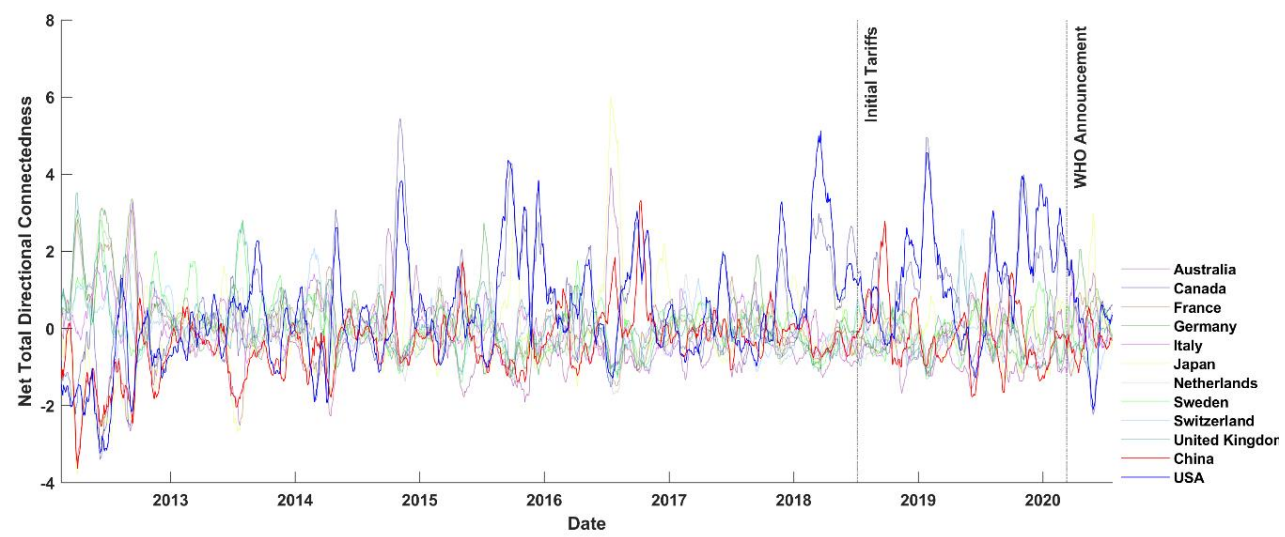

Figure. 6. Country centralities and net total directional connectedness through time (Daily Indexes with Timing Adjustment)

Time series of network measures through time: (A) Katz centrality from LASSO estimation; (B) Degree centrality from VAR estimation; and (C) Net total directional connectedness from variance decomposition estimation. The initial U.S. imposition of Chinese-specific tariffs took place on July 6, 2018 and the WHO's initial announcement of Covid-19 pandemic was on March 11, 2020. The VAR and LASSO networks are estimated in rolling 30-day intervals using daily open-close index returns adjusted for timing synchronization in Table 8. 


\subsection{Different Length of Moving Averages}

In the main analysis we depict network analysis results averaged over rolling 15-day intervals. In this section, we conduct robustness analysis on the length of our rolling average, and allow for rolling 30-day intervals (Figure 7) and rolling 60-day intervals (Figure 8). We find that our main results are unchanged. Using high-frequency data on ETFs, we show that China became central well before the announcement of tariffs or the pandemic while the centrality of the U.S. has decreased during these times.

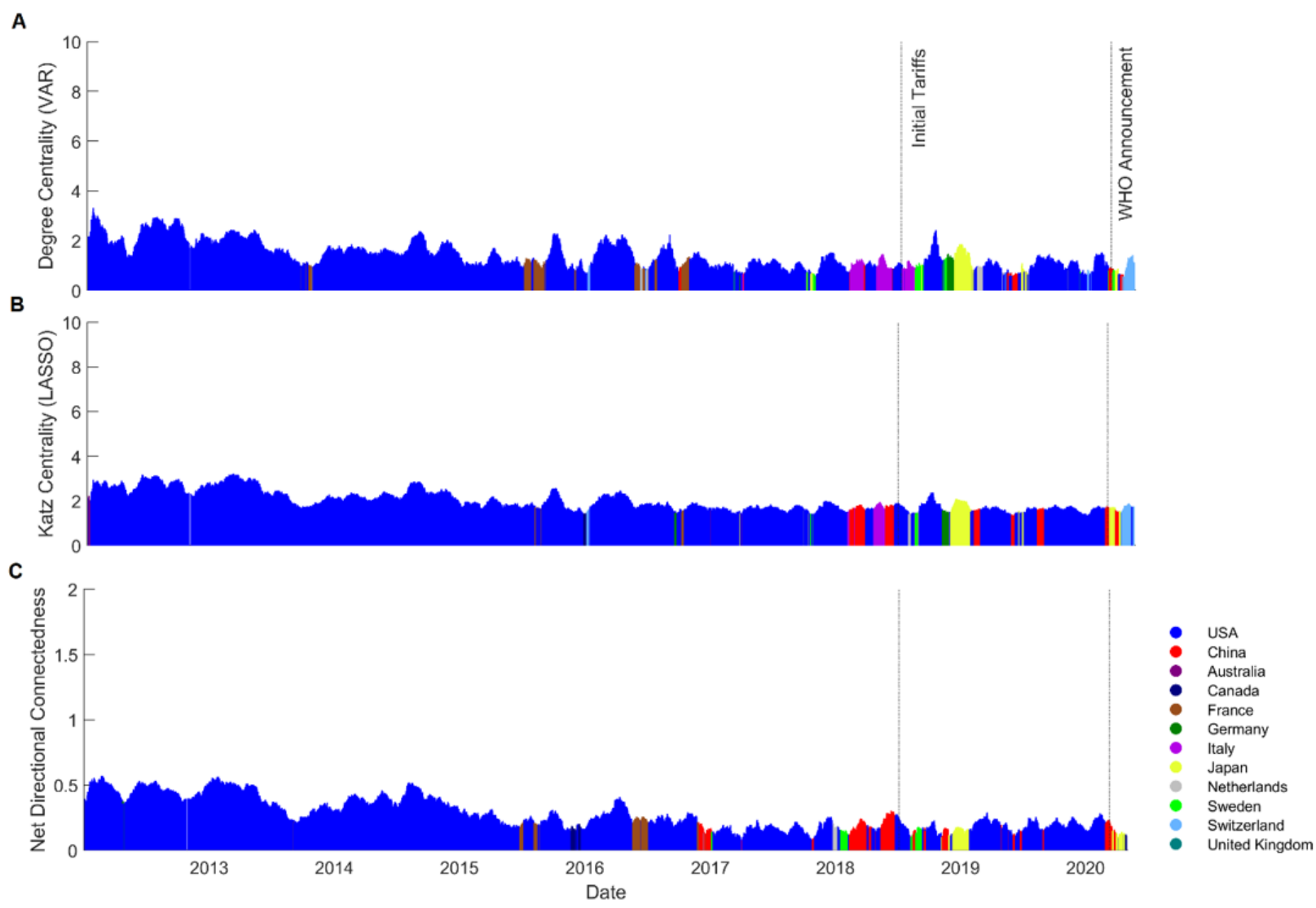

Figure. 7. Maximum country centralities and net total directional connectedness through time (30-day average)

Time series of maximum values of network measures through time: (A) Degree centrality from VAR estimation; (B) Katz centrality from LASSO estimation; and (C) Net total directional connectedness from variance decomposition estimation. For each point in time, only the maximum value and corresponding country colour are depicted. The values are averaged over rolling 30-day intervals. The initial U.S. imposition of Chinese-specific tariffs took place on July 6, 2018 and the WHO's initial announcement of Covid-19 pandemic was on March 11, 2020. 


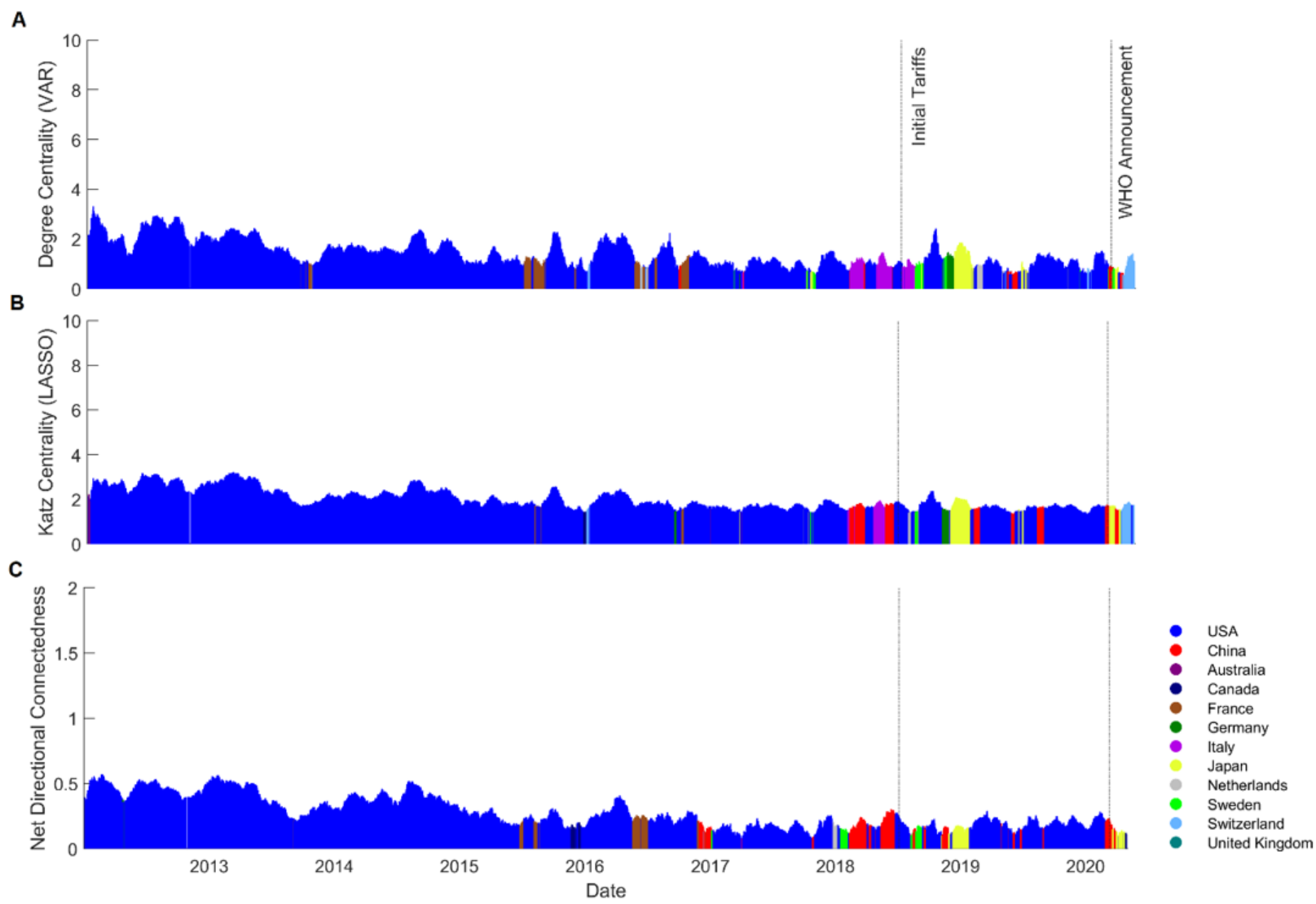

Figure. 8. Maximum country centralities and net total directional connectedness through time (60-day average)

Time series of maximum values of network measures through time: (A) Degree centrality from VAR estimation; (B) Katz centrality from LASSO estimation; and (C) Net total directional connectedness from variance decomposition estimation. For each point in time, only the maximum value and corresponding country colour are depicted. The values are averaged over rolling 60-day intervals. The initial U.S. imposition of Chinese-specific tariffs took place on July 6, 2018 and the WHO's initial announcement of Covid-19 pandemic was on March 11, 2020.

\section{Conclusion}

Network theory and high-frequency financial data show that the world has started to move from a unipolar system to a bipolar one. Is this phenomenon captured by countryspecific index returns or low-frequency data? The answer is no, based on the analysis

of the daily returns data. We show that the high-frequency financial data is forwardlooking in capturing the rise of centrality of China. Simultaneously, the data show that 
some European countries also became more financially central during the pandemic, but none quite as central as either the U.S. or China. We posit that Europe is fragmented enough that it does not offer a counterweight to the newly formed bipolar relationship between the U.S. and China. It is clear that both political and epidemiological forces can significantly affect the structure of global networks. The high centrality of the U.S. and its political hegemony in the unipolar system once gave it unchallenged influence over global power, economics, culture, and moral leadership. Our data shows that the U.S. has recently lost its edge, the world map becoming more bipolar as the U.S. has lost its central authority and power.

It must be underscored that the centrality of China is a very recent phenomenon, and may be transient. It is ironic, however, that one of the first indications of a newly bipolar financial system was caused by the strained relationship between the U.S. and China, at a time when scientific collaboration between the nations is especially needed to fight the pandemic and develop a vaccine against the coronavirus (Silver, 2020). It remains to be seen if the "Thucydides trap" of conflict during hegemonic decline can be prevented. As we move from a unipolar world to a bipolar one, we must prevent further escalation and instead pursue scientific collaboration and cultural exchange. 


\section{References}

Acemoglu, D., Carvalho, V. M., Ozdaglar, A., Tahbaz-Salehi, A., 2012. The network origins of aggregate fluctuations. Econometrica 80, 1977-2016.

Acharya, V., Jiang, Z., Richmond, R., von Thadden, E.-L., 2020. Divided we fall: International health and trade coordination during a pandemic. NBER WP 28176.

Antràs, P., Redding, S. J., Rossi-Hansberg, E., 2020. Globalization and pandemics. NBER Working Paper 27840 .

Battiston, S., Farmer, J. D., Flache, A., Garlaschelli, D., Haldane, A. G., Heesterbeek, H., Hommes, C., Jaeger, C., May, R., Scheffer, M., 2016. Complexity theory and financial regulation. Science 351, 818-819.

Billio, M., Getmansky, M., Lo, A. W., Pelizzon, L., 2012. Econometric measures of connectedness and systemic risk in the finance and insurance sectors. Journal of Financial Economics 104, 535-559.

Brodeur, A., Gray, D. M., Islam, A., Bhuiyan, S., 2020. A literature review of the economics of Covid-19. IZA Discussion Paper .

Chinco, A., Clark-Joseph, A. D., Ye, M., 2019. Sparse signals in the cross-section of returns. The Journal of Finance 74, 449-492.

Cieslak, A., Morse, A., Vissing-Jorgensen, A., 2019. Stock returns over the fomc cycle. The Journal of Finance 74, 2201-2248.

Diebold, F. X., Yılmaz, K., 2014. On the network topology of variance decompositions: Measuring the connectedness of financial firms. Journal of Econometrics 182, 119-134.

Ernst, T., 2020. Stock-specific price discovery from ETFs. Working Paper . 
Gao, L., Han, Y., Li, S. Z., Zhou, G., 2018. Market intraday momentum. Journal of Financial Economics 129, 394-414.

Gofman, M., Segal, G., Wu, Y., Forthcoming. Production networks and stock returns: The role of vertical creative destruction. Review of Financial Studies .

Gu, S., Kelly, B., Xiu, D., 2020. Empirical asset pricing via machine learning. The Review of Financial Studies 33, 2223-2273.

Hasbrouck, J., 1995. One security, many markets: Determining the contributions to price discovery. The Journal of Finance 50, 1175-1199.

Hastie, T., Tibshirani, R., Friedman, J., 2001. The Elements of Statistical Learning: Data Mining, Inference, and Prediction. Springer Science \& Business Media, Berlin.

Holden, C. W., Jacobsen, S., 2014. Liquidity measurement problems in fast, competitive markets: Expensive and cheap solutions. The Journal of Finance 69, 1747-1785.

Jackson, M. O., 2014. Networks in the understanding of economic behaviors. Journal of Economic Perspectives 28, 3-22.

Koop, G., Pesaran, M. H., Potter, S. M., 1996. Impulse response analysis in nonlinear multivariate models. Journal of Econometrics 74, 119-147.

LeBaron, B., Tesfatsion, L., 2008. Modeling macroeconomies as open-ended dynamic systems of interacting agents. American Economic Review 98, 246-50.

Mantegna, R. N., Stanley, H. E., 1995. Scaling behaviour in the dynamics of an economic index. Nature $376,46-49$.

McKibbin, W. J., Fernando, R., 2020. The global macroeconomic impacts of Covid-19: Seven scenarios. CAMA Working Paper . 
Ossa, R., 2014. Trade wars and trade talks with data. American Economic Review 104, 4104-46.

Pesaran, H. H., Shin, Y., 1998. Generalized impulse response analysis in linear multivariate models. Economics letters 58, 17-29.

Rapach, D. E., Strauss, J. K., Zhou, G., 2013. International stock return predictability: what is the role of the united states? The Journal of Finance 68, 1633-1662.

Silver, A., 2020. Scientists in china say us government crackdown is harming collaborations. Nature 583, 341-342.

White, H., 1980. A heteroskedasticity-consistent covariance matrix estimator and a direct test for heteroskedasticity. Econometrica pp. 817-838.

WHO-Report, 2020. Coronavirus disease (Covid-19) (available at https: //covid19. who. int/). 


\section{Appendices}

\section{A. Network Measures Through Time}

This appendix reports the dynamics of the degree centrality and Katz centrality for the estimated network measures from our minute-by-minute ETF returns. In Figure 9, the Katz centrality from VAR estimation is presented and in Figure 10, the degree centrality is presented from LASSO estimation of the lead-lag relationships between country-specific ETFs. The results are consistent with main results in the paper.

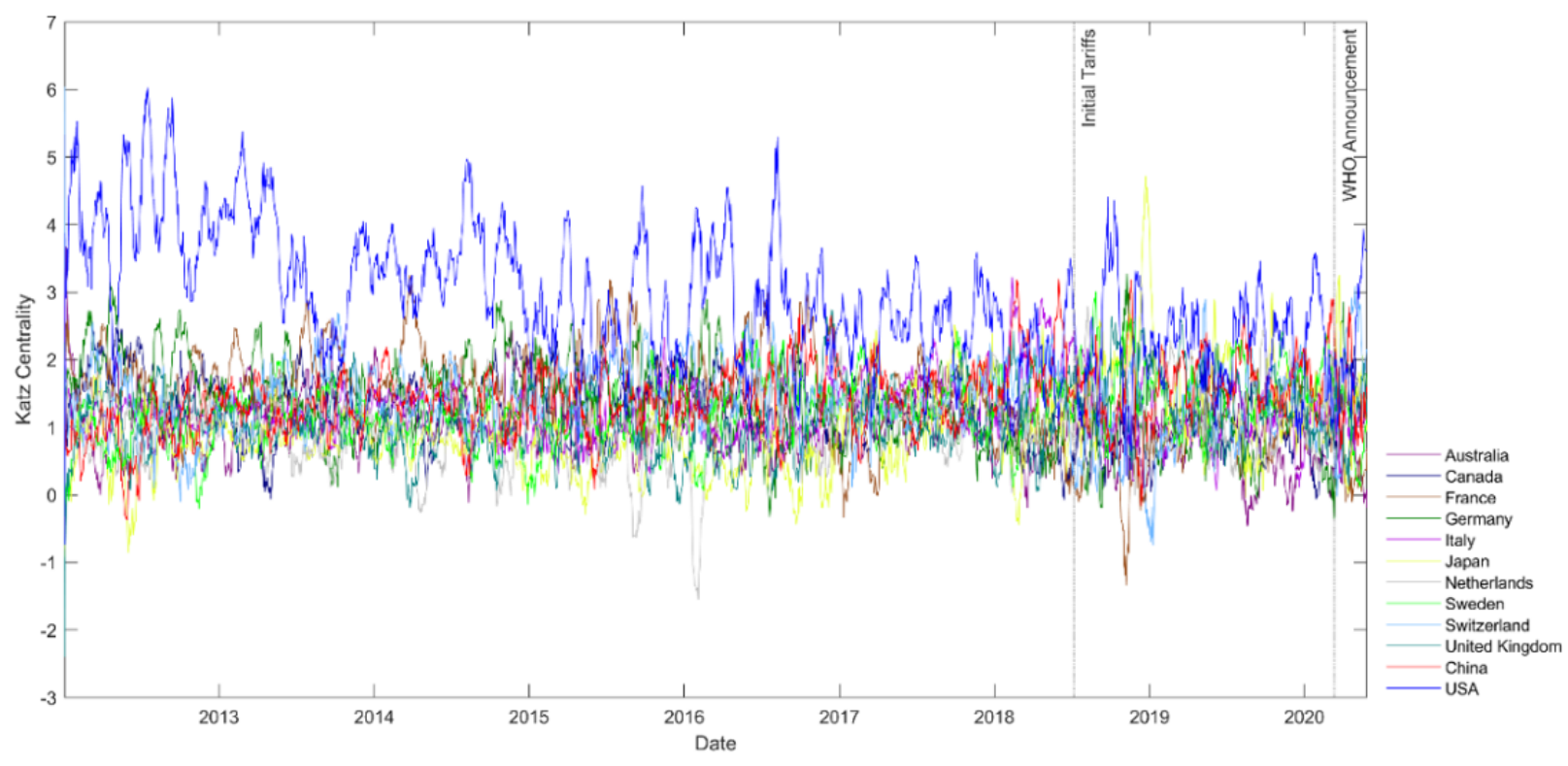

Figure. 9. Katz centrality through time (VAR estimation)

Time series of degree centralities (VAR estimation) for each country-specific ETF through time. We estimate the lead-lag relationships between country-specific ETFs via VAR using minute-by-minute returns in each day. The Katz centralities are computed each day and averaged over rolling 15-day intervals. The initial U.S. imposition of Chinese-specific tariffs took place on July 6, 2018 and the WHO's initial announcement of Covid-19 as a pandemic happened on March 11, 2020. 


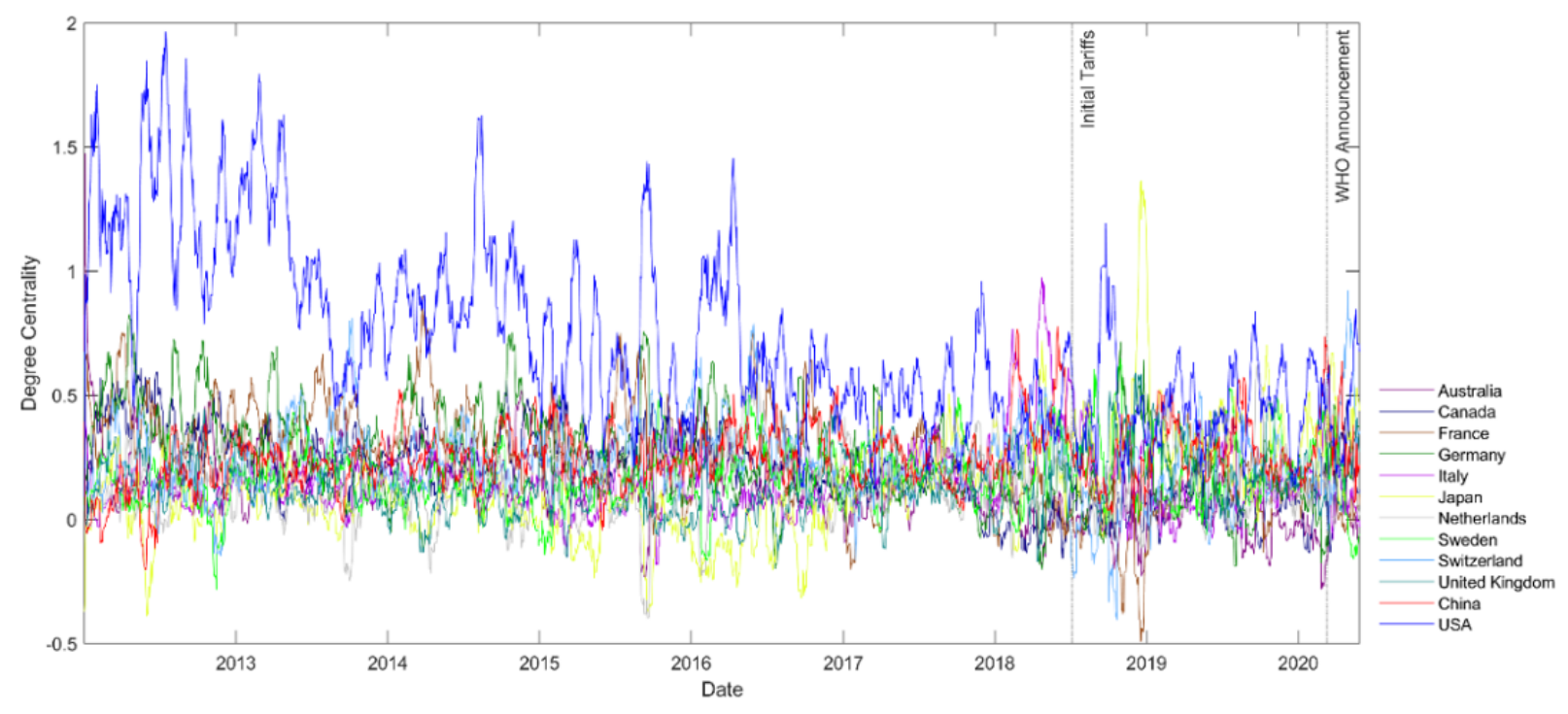

Figure. 10. Degree centrality through time (LASSO estimation)

Time series of degree centralities of each country-specific ETF through time. We estimate the lead-lag relationships between country-specific ETFs via LASSO using minute-by-minute returns in each day. The degree centralities are computed each day and averaged over rolling 15-day intervals. The initial U.S. imposition of Chinese-specific tariffs took place on July 6, 2018 and the WHO's initial announcement of Covid-19 as a pandemic happened on March 11, 2020. 


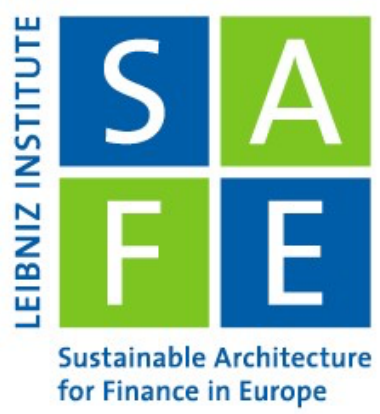

\section{Recent Issues}

No. 303 Ankit Kalda, Benjamin Loos, Alessandro Previtero, Andreas Hackethal

No. 302

No. 301

No. 300

No. 299

No. 298

Calebe de Roure, Emanuel Moench, Loriana Pelizzon, Michael Schneider

No. 297 Dimitrios Kostopoulos, Steffen Meyer, Charline Uhr

No. 296 Reint Gropp, Thomas Mosk, Steven Ongena, Ines Simac, Carlo Wix

No. 295 Besart Avdiu, Alfons J. Weichenrieder

No. 294 Christian Alemán, Christopher Busch, Alexander Ludwig, Raül Santaeulàlia-Llopis

No. 293 Christoph Hambel, Holger Kraft, André Meyer-Wehmann

No. 292 Andrea Modena

No. 291 Loriana Pelizzon, Satchit Sagade, Katia Vozian
Smart (Phone) Investing?

A Within Investor-Time Analysis of New Technologies and Trading Behavior

The FOMC Risk Shift

Risk Taking, Preferences, and Beliefs: Evidence from Wuhan

An Extensible Model for Historical Financial Data with an Application to German Company and Stock Market Data

Motivated Beliefs and the Elderly's Compliance with COVID-19 Measures

OTC Discount

Ambiguity and Investor Behavior

Supranational Rules, National Discretion: Increasing Versus Inflating Regulatory Bank Capital?

Financing Costs and the Efficiency of PublicPrivate Partnerships

Evaluating the Effectiveness of Policies Against a Pandemic

When Should Retirees Tap Their Home Equity?

Recapitalization, Bailout, and Long-run Welfare in a Dynamic Model of Banking

Resiliency: Cross-Venue Dynamics with Hawkes Processes 